\title{
VALIDITY AND RELIABILITY OF THE FLOURISHING SCALE: LATVIAN VERSION
}

\author{
Inese Sadauska \\ University of Latvia, Latvia
}

Aleksandrs Koḷesovs

University of Latvia, Latvia

\begin{abstract}
The objective of this study was to assess the psychometric properties of the Latvian version of the Flourishing Scale (FS), created by Diener et al. (2010). FS is a brief self-report measure of the respondent's well-being and success in areas of relationships, self-esteem, purpose, and optimism. The scale provides a single score across 8 items. The original FS was translated to Latvian and then back to English. The Satisfaction with Life Scale and Meaning in Life Questionnaire was applied for testing the convergent validity of the FS. Participants of the study were 191 people, ranged in age from 19 to 68 (159 women, mean age $M=30.62$, $S D=9.50$ ). Reliability analysis, exploratory and confirmatory factor analysis (EFA and CFA) of the scale were performed. EFA indicated a one-factor structure. Results showed that the Latvian version of FS has good psychometric properties and demonstrated convergent validity. Testing of the original model by CFA resulted in acceptable fit indices.
\end{abstract}

Keywords: factorial validity, flourishing, Flourishing Scale, subjective well-being, well-being.

\section{Introduction}

During the recent decade, the variety of measurements of well-being has grown, reflecting the general interest of positive psychology in understanding of what are the necessary components for human happiness (Linton, Dieppe, \& Medina-Lara, 2016; Cooke, Melchert, \& Connor, 2016). The differences in selfreport measures for well-being stem from the conceptual and theoretical basis of how well-being is defined. There are two broader traditions in research on wellbeing, drawing distinction between concepts of eudaimonic and hedonic wellbeing, both of which are rooted in the ancient Greek philosophy of Aristotle (Aristotelis, 1985) and Epicures (Epikūrs, 2007). Hedonic well-being is understood as primarily involving pleasure. It tends to be more individualistic and is based upon how good one feels about life, and it is empirically measured by using, for instance, the Satisfaction with Life Scale (SWLS, Diener, Emmons, Larsen, \& Griffin, 1985) assessing global evaluations of one's life. SWLS is a brief, easily administered, and widely used measure that is based on Diener's (1984) tripartite model of subjective well-being consisting of life 
satisfaction (the cognitive component), positive affect, and absence of negative affect (affective components).

Meanwhile, eudaimonic well-being, as defined by Aristotle (1985), means happiness consisting of pleasure and virtue, the highest cultivation of personal character; it is a good life. While there is strong consensus on what variables constitute hedonic well-being (i.e., satisfaction, absence of distress, behaviors seeking these experiences, etc.), there is less agreement on the conceptualization of eudaimonic well-being. Psychologists have reframed Aristotle's formula for happiness in terms of pleasure and psychosocial meaning, involving pleasure but emphasizing meaningfulness and growth (Ryan \& Deci, 2001). It tends to be more humanistic and based upon how meaningful one's life feels, besides to simply how good it feels and includes a positive attitude towards life as expressed by positive emotions, feelings of happiness, uplifting and satisfaction with life. Ryff's and Keyes's (1995) measure of Psychological Well-Being (PWB) represents this tradition and assesses feeling good about one's life on six dimensions: self-acceptance, environmental mastery, positive relationships, meaning in life, personal growth, and autonomy. Deci and Ryan (2000) in their self-determination theory (SDT) posited that happiness can be achieved by satisfying three specific types of human needs for autonomy, relatedness, and competence. Huta (2015) has outlined four common core elements of eudaimonic well-being that appear across all theories: authenticity and being one's true self, meaning and purpose in the broader context of one's ecosystem, excellence and striving for higher standards in life, and growth and actualization of one's potential.The implication, as noted by Kashdan et al. (2008), is that eudaimonic well-being is morally superior as compared to hedonic well-being and that happiness is just "the product (or perhaps a by-product) of the pursuit of self-realization rather than the objective being sought” (Waterman, 2007, 612).

Recently, however, this dualism in well-being research has been questioned, suggesting that instead of focusing on the distinction between eudaimonia and hedonism, we should treat them as different but complementary and highly related facets of the same phenomena (Kashdan, Biswas-Diener, \& King, 2008; Giuntoli \& Vidotto, 2020; Goodman, Disabato, Kashdan, \& Kauffman, 2017; Sheldon, 2018). The concept of flourishing has been introduced to integrate the two approaches. Numerous definitions exist of flourishing, and different authors have introduced different sets of flourishing dimensions. Keyes (2002) suggests that flourishing is the presence of mental health and in measuring flourishing combines both eudaimonic (Ryff's six psychological well-being dimensions along with five dimensions of social wellbeing) and hedonic (happiness or life satisfaction) approaches. Seligman (2011) has developed the PERMA model suggesting that flourishing comprises five components: positive emotions, engagement, relationships, and meaning and 
accomplishment (hence the PERMA acronym). Huppert and So (2013) have defined flourishing as a combination of feeling good and functioning effectively or "life going well", identifying ten features of positive mental functioning: competence, emotional stability, engagement, meaning, optimism, positive emotion, positive relationship, resilience, self-esteem, and vitality. Sheldon (2018) proposed the Eudaimonic activity model of flourishing that distinguishes three aspects: eudaimonic practices, satisfying psychosocial experiences, and subjective well-being as defined by Diener et al. (1985). The first two elements in his model are a combination of the three needs of SDT (Deci \& Ryan, 2000) and six dimensions of PWB (Ryff \& Keyes, 1995).

The eight-item Flourishing Scale was designed by Diener et al. (2010) to measure social-psychological prosperity to complement the existing measures for subjective well-being by addressing the several universal human psychological needs addressed in humanistic psychology theories. The FS includes such components as positive relationships, contribution towards the well-being of others, purpose in life, competence, optimism, engagement, and self-esteem.

Since its development, FS has been validated across different cultural contexts, age groups, and languages (Tong \& Wang, 2017, Schotanus-Dijkstra, Peter, Drossaert, Pieterse, Bolier, Walburg, \& Bohlmeijer, 2016, Villieux, Sovet, Jung, \& Guilbert, 2016, Sumi, 2014, Giuntoli, Ceccarini, Sica, \& Caudek, 2017, Kyriazos, Stalikas, Prassa, Yotsidi, Galanakis, \& Pezirkianidis, 2018, Silva \& Caetano, 2013, Ramirez-Maestre, Correa, Rivas, Lopez-Martinez, SerranoIbáñez, \& Esteve, 2107, Didino, Taran, Barysheva, \& Casati, 2019).

There are several measures of psychological well-being adapted into Latvian, for instance, SWLS (Upmane, 2012) and Meaning in Life Questionnaire (Kolesovs, 2019). Research in Latvia reveals a significant correlation between satisfaction with life and perception of one's financial wellbeing: the higher the perceived financial well-being, the higher the estimated satisfaction with life and vice versa (Upmane, 2012; Kolesovs, 2017). The objective of the present study is to analyze the psychometric properties of the Latvian version of the FS, testing its validity, reliability, and factor structure, thus adapting a new measure of psychological well-being into the Latvian language.

\section{Method}

\section{Participants}

A sample of 191 adults (83\% female, aged from 19 to 68 years, $M=30.62$, $S D=9,50$ ) were interviewed. The snowball convenience sample involved 
psychology students (52\%) and their friends or relatives, 63\% were employed, $56 \%$ were either married or in a relationship.

\section{Measures}

The Flourishing Scale (FS; Diener, Wirtz, Tov, Kim-Prieto, Choi, Oishi, \& Biswas-Diener, 2010) is a 7-point Likert scale with 8 items (from strong disagreement to strong agreement) that measures participant's beliefs about such areas of their life as positive relationships, meaning, and purpose in life, as well as a sense of competence. Scores can range from 8 to 56 (demonstrating strong agreement on all scales).

Series of studies on the FS demonstrated reliability scores with Cronbach's alpha in the range of .78 - .95. The FS has revealed one strong factor with an eigenvalue of 4.24 , accounting for $53 \%$ of the variance (Diener et al., 2010). The later adaptations of the FS in various languages demonstrated a similar onefactor structure of the scale (e.g., Didino et al., 2019; Ramírez-Maestre et al., 2017; Tong \&Wang, 2017; Hone et al., 2014; Perera, Meade, \& DiPonio, 2018).

The Satisfaction with Life Scale (SWLS; Diener et al., 1985). Five items assess the cognitive evaluation of life as desirable on a 7-point Likert scale with responses varying from strong disagreement to strong agreement. The adaptation of the scale in Latvian by Upmane (2012) was used. In the current study, the Cronbach's alpha of the SWLS was .87.

Meaning in Life Questionnaire (MLQ; Steger, Frazier, Oishi, \& Kaler, 2006). The ten-item MLQ measures the presence and searches for meaning and purpose in life. Only the 5-item presence subscale (MLQ-P) was used. Items are rated on 7-point Likert scale with responses varying from strong disagreement to strong agreement. The adaptation in Latvian demonstrated good internal consistency of the subscale (Kolesovs, 2019). In the current study, the Cronbach's alpha of the MLQ-P was .91.

Self-reported health status was assessed by a single item measurement of participant's self-assessment of physical health in comparison to other people of the same age on a 5-point scale from very poor to very good.

Self-reported economic well-being was assessed by a single item measurement of participant's self-assessment of their family's economic wellbeing on a 5-point scale from missing even the most basic things to can afford anything I want.

\section{Procedure}

The FS translation procedure consisted of two steps. Firstly, the English version of the FS was simultaneously translated into Latvian by independent translators. Secondly, the resulting Latvian version was back-translated and compared to the original English version. 
All participants were informed of the aim of the study, personal anonymity, and the confidentiality of the survey. Data collection occurred in the winter of 2019.

Analyses of the data obtained were performed using the lavaan R package Version i386 3.5.2 and IBM SPSS Statistics Version 22.0.

\section{Results}

The data were analyzed in three steps: the exploratory factor analyses (EFA), the confirmatory factor analyses (CFA), and convergent validity analyses, which included the testing relationship of the FS with life satisfaction.

\section{Exploratory factor analysis}

The exploratory factor analysis (EFA) was performed applying principal component analyses extraction with Varimax rotation. Before performing EFA, the suitability of data for factor analysis was assessed. The Kaiser Meyer-Olkin value was .88, demonstrating a good level of sampling adequacy. Bartlett's Test of Sphericity reached statistical significance, confirming that data were factorable, $\chi^{2}(28)=703.59, \mathrm{p}<.001$. The principal components analysis revealed the presence of one factor with an eigenvalue above 1 (4.37), accounting for $55 \%$ of the variance. The factor loading ranged from .83 to .50. Therefore, only one factor characterized the FS (Table 1).

Table 1 Exploratory Factor Analysis of Flourishing Scale

\begin{tabular}{|l|c|c|}
\hline \multicolumn{1}{|c|}{ Flourishing Scale item } & \multicolumn{2}{c|}{ Factor structure } \\
\hline \multicolumn{1}{|c|}{} & Loading & $\mathrm{h}^{2}$ \\
\hline FS1 I lead a purposeful and meaningful life & .77 & .59 \\
\hline FS2 My social relationships are supportive and rewarding & .73 & .54 \\
\hline FS3 I am engaged and interested in my daily activities & .74 & .55 \\
\hline $\begin{array}{l}\text { FS4 I actively contribute to the happiness and well-being of } \\
\text { others }\end{array}$ & .50 & .25 \\
\hline $\begin{array}{l}\text { FS5 I am competent and capable in the activities that are } \\
\text { important to me }\end{array}$ & .70 & .49 \\
\hline FS6 I am a good person and live a good life & .79 & .62 \\
\hline FS7 I am optimistic about my future & .80 & .65 \\
\hline FS8 People respect me & .83 & 69 \\
\hline \multicolumn{2}{|l|}{} \\
\hline Factor and scale characteristics & Value \\
\hline Eigenvalue & 4.37 \\
\hline Explained Variance & $55 \%$ \\
\hline Cronbach’s Alpha & .88 \\
\hline$M(S D)$ & $42,27(7.60)$ \\
\hline
\end{tabular}




\section{Confirmatory factor analysis}

An eight-item, one-factor model, as identified by EFA was investigated. The initial model showed low level of fit to data $\chi^{2}(20)=61.075, p<.001$. The original model's CFA $=.90$ and TLI $=.86$ indicated acceptable fit, but the RMSEA of .13 failed to reach the recommended values between .05 and .08 , indicating a not well-fitted model. Given the high RMSEA value, the model was statistically modified by correlating errors between Item 2 and Item 4 (see Fig.1). This produced a better fitting model, with CFI $=.94$, TLI $=.92$, and RMSEA (.08), indicating satisfactory fit. These analyses confirm the unidimensional factor structure of the FS. Fit statistics for both models are reported in Table 2.

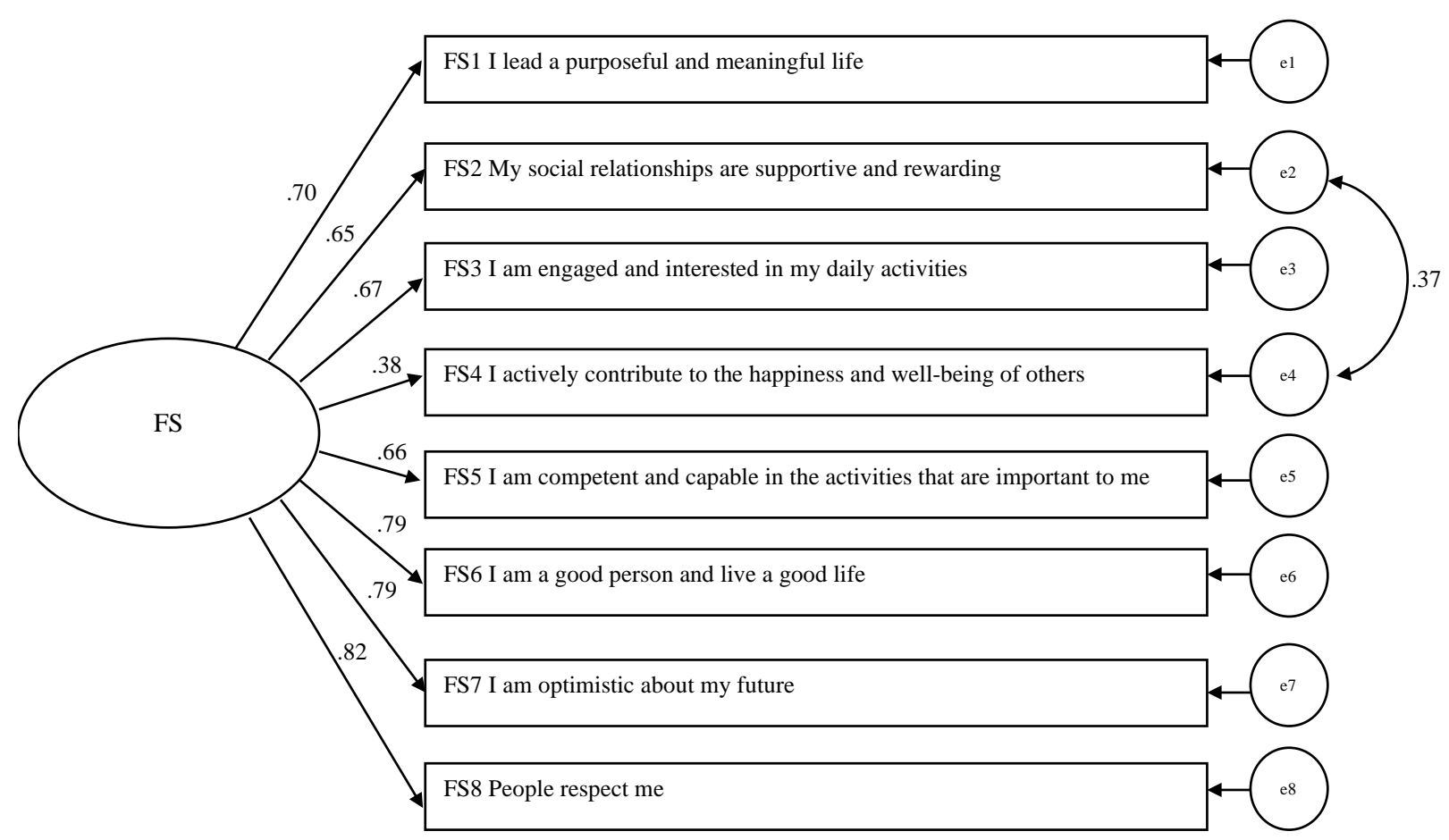

Figure1 Flourishing Scale: One Factor Confirmatory Factor Model

Table 2 Goodness of fit Statistics for the Tests of Factorial Validity of the Flourishing Scale

\begin{tabular}{|c|c|c|c|c|c|c|}
\hline FS & $\chi^{2}$ & $d f$ & CFI & TLI & SRMR & $\begin{array}{c}\text { RMSEA } \\
(90 \% \text { CI })\end{array}$ \\
\hline Model 1 & 61.075 & 20 & .896 & .854 & .063 & .104 \\
\hline Model 2 & 43.301 & 19 & .938 & .909 & .050 & .82 \\
\hline
\end{tabular}

Model 1 - original model; model 2 - Errors of Items 2 and 4's covary. 


\section{Testing convergent validity}

To investigate the convergent validity of the FS, we correlated single-item health status and economic well-being questions, SWLS, and MLQ-P with FS (see Table 3). There were strong, positive correlations between the FS and life satisfaction, as well as the presence of meaning and purpose in life. FS is positively, significantly associated with health and economic well-being. These results are consistent with published reports on FS (Diener et al., 2010, Tong \& Wang, 2017, Villieux et al., 2016, Sumi, 2014, Silva \& Caetano, 2013).

Table 3 Correlations between the Flourishing Scale, SWLS, MLQ-P, Health and Economic Well-being

\begin{tabular}{|l|c|c|c|c|c|}
\hline \multicolumn{1}{|c|}{ Measures } & FS & SWLS & MLQ-P & Health & $\begin{array}{c}\text { Economic } \\
\text { well-being }\end{array}$ \\
\hline FS & - & & & & \\
\hline SWLS & $.703^{* *}$ & - & & & \\
\hline MLQ-P & $.713^{* *}$ & $.558^{* *}$ & - & & \\
\hline Health & $.392^{* *}$ & $.369^{* *}$ & $.193^{*}$ & - & - \\
\hline $\begin{array}{l}\text { Economic well- } \\
\text { being }\end{array}$ & $.279^{* *}$ & $.400^{* *}$ & $.220^{* *}$ & $.286^{* *}$ & \\
\hline$* * p<.01 ;{ }^{*} p<.05$ & & & & \\
\hline
\end{tabular}

\section{Discussion and Conclusions}

The objective of the current study was to adapt FS into the Latvian language and provide empirical evidence regarding its psychometric qualities. The results of exploratory and confirmatory factor analyses were consistent with findings of the Diener et al. (2010) original study and with those observed in other national or cultural samples (Villieux et al., 2016, Silva \& Caetano, 2013, Tong \& Wang, 2017, Sumi, 2014, Didino et al., 2019, Ramirez-Maestre, 2017).

Good reliability of the scale was indicated with Cronbach's alpha coefficient of .88 and it was consistent with the original FS (Diener et al., 2010). FS correlations with measures capturing well-being (SWLS, MLQ-P, health, and economic well-being) were strong and positive, demonstrating the scale's convergent validity. CFA supported the unidimensionality of the FS factor structure with acceptable factor fit.

Each item of the FS represents a distinct feature of well-being and psychosocial functioning. Nevertheless, as noted by Didino et al. (2019), some of the previous studies on FS allowed error covariance between items so that the acceptable values for the one-factor model fit indices in CFA could be reached. Errors between different items were correlated depending on the study (Hone Jarden, \& Schofield, 2014, Howell \& Buro, 2015, Perera et al., 2018, 
Tong \& Wang, 2017, Momtaz et al., 2016, Kyriazos et al., 2018), and with some of the correlation patterns overlapping in various studies. However, they have not been based on theoretical assumptions or further investigated and explained. We correlated errors between items 2 ("My social relationships are supportive and rewarding") and 4 ("I actively contribute to the happiness and well-being of others") to improve model fit. It suggests that there could be a factor that might account for the error variances of the two items. Didino et al. (2019) observed similar error correlations in the sample of older adults, with the addition of item 8 ("People respect me"), speculating that these items measure social relationships. In addition, this might also suggest culture-specific dimensions to flourishing. However, future analyses are required.

There are some limitations to our study. We have used a convenience sample of predominantly students (52\%), with the mean age of 30,62 and the majority of them female (83\%). Therefore, broader samples, representative of the adult population, could be studied in the future. The psychometric properties of FS should be examined further in different populations, for instance, adolescents or older adults. Furthermore, test-retest reliability of the Latvian version should be evaluated.

Overall, the present version of the FS is reliable and suitable for researchers and practitioners planning to study new aspects of well-being in Latvian cultural context.

\section{References}

Aristotelis. (1985). Nicomachean Ethics. Rīga: Zvaigzne.

Cooke, P. J., Melchert, T. P., \& Connor, K. (2016). Measuring Well-Being: A Review of Instruments. The Counseling Psychologist, 44(5), 730-757. https://doi.org/10.1177/ 0011000016633507

Deci, E. L., \& Ryan, R. M. (2000). The "What" and "Why” of Goal Pursuits: Human Needs and the Self-Determination of Behavior. Psychological Inquiry, 11(4), 227. https://doi.org/10.1207/S15327965PLI1104_01

Didino, D., Taran, E. A., Barysheva, G. A., \& Casati, F. (2019). Psychometric evaluation of the Russian version of the flourishing scale in a sample of older adults living in Siberia. Health and Quality of Life Outcomes, 17(1). Scopus. https://doi.org/10.1186/s12955019-1100-6

Diener, E. (1984). Subjective well-being. Psychological Bulletin, 95(3), 542-575. https://doi.org/10.1037/0033-2909.95.3.542

Diener, E., Emmons, R. A., Larsen, R. J., \& Griffin, S. (1985). The Satisfaction With Life Scale. Journal of Personality Assessment, 49(1), 71. https://doi.org/10.1207/ s15327752jpa4901_13

Diener, E., Wirtz, D., Tov, W., Kim-Prieto, C., Choi, D., Oishi, S., \& Biswas-Diener, R. (2010). New well-being measures: short scales to assess flourishing and positive and negative feelings. Social Indicators Research, 97(2), 143-156. https://doi.org/10.1007/ s11205-009-9493-y 
Epikūrs. (2007). Letters. Insights. Fragments. Rīga: Liepnieks \& Rītups

Giuntoli, L., Ceccarini, F., Sica, C., \& Caudek, C. (2017). Validation of the Italian Versions of the Flourishing Scale and of the Scale of Positive and Negative Experience. SAGE Open, 7, 1-12. https://doi.org/10.1177/2158244016682293

Giuntoli, L., \& Vidotto, G. (2020). Exploring Diener's Multidimensional Conceptualization of Well-Being Through Network Psychometrics. Psychological Reports, 124(2), 896919. https://doi.org/10.1177/0033294120916864

Goodman, F., Disabato, D., Kashdan, T., \& Kauffman, S. (2017). Measuring well-being: A comparison of subjective well-being and PERMA. The Journal of Positive Psychology, 1-12. https://doi.org/10.1080/17439760.2017.1388434

Hone, L., Jarden, A., \& Schofield, G. (2014). Psychometric Properties of the Flourishing Scale in a New Zealand Sample. Social Indicators Research, 119(2), 1031-1045. https://doi.org/10.1007/s11205-013-0501-x

Howell, A. J., \& Buro, K. (2015). Measuring and Predicting Student Well-Being: Further Evidence in Support of the Flourishing Scale and the Scale of Positive and Negative Experiences. Social Indicators Research, 121(3), 903-915. https://doi.org/10.1007/ s11205-014-0663-1

Huppert, F. A., \& So, T. T. C. (2013). Flourishing Across Europe: Application of a New Conceptual Framework for Defining Well-Being. Social Indicators Research, 110(3), 837-861. https://doi.org/10.1007/s11205-011-9966-7

Huta, V. (2015). The Complementary Roles of Eudaimonia and Hedonia and How They Can Be Pursued in Practice. In Joseph, S. (Ed.), Positive Psychology in Practice. Promoting Human Flourishing in Work, Health, Education, and Everyday Life (159-182). New Jersey: John Wiley \& Sons, Inc.

Kashdan, T. B., Biswas-Diener, R., \& King, L. A. (2008). Reconsidering happiness: The costs of distinguishing between hedonics and eudaimonia. The Journal of Positive Psychology, 3(4), 219-233. https://doi.org/10.1080/17439760802303044

Keyes, C. L. M. (2002). The mental health continuum: From languishing to flourishing in life. Journal of Health and Social Behavior, 43(2), 207-222. http://dx.doi.org/10.2307/ 3090197

Kolesovs, A. (2017). Individual future orientation and demographic factors predicting life satisfaction. Proceedings of the International Scientific Conference, Vol. 1, May 26th27th, 534-543. http://10.17770/sie2017vol1.2448

Kolesovs, A. (2019). Adaptation of the meaning in life questionnaire in Latvian. Sociālo Zinātñu Vēstnesis, 1(28), ISSN 1691-1881, eISSN 2592-8562

Kyriazos, T. A., Stalikas, A., Prassa, K., Yotsidi, V., Galanakis, M., \& Pezirkianidis, C. (2018). Validation of the Flourishing Scale (FS), Greek version and evaluation of two well-being models. Psychology, 9(07), 1789-1813. https://doi.org/10.4236/ psych.2018.97105

Linton, M.-J., Dieppe, P., \& Medina-Lara, A. (2016). Review of 99 self-report measures for assessing well-being in adults: Exploring dimensions of well-being and developments over time. BMJ Open, 6(7), e010641. https://doi.org/10.1136/bmjopen-2015-010641

Momtaz, Y. A., Hamid, T. A., Haron, S. A., \& Bagat, M. F. (2016). Flourishing in later life. Archives of Gerontology and Geriatrics, 63, 85-91. https://doi.org/10.1016/j. archger.2015.11.001

Perera, M. J., Meade, M. A., \& DiPonio, L. (2018). Use and psychometric properties of the Flourishing Scale among adults with spinal cord injury. Rehabilitation Psychology, 
63(2), 250-257. https://doi.org/10.1037/rep0000184

Ramírez-Maestre, C., Correa, M., Rivas, T., López-Martínez, A. E., Serrano-Ibáñez, E. R., \& Esteve, R. (2017). Psychometric characteristics of the Flourishing Scale-Spanish Version (FS-SV). The factorial structure in two samples: Students and patients with chronic pain. Personality and Individual Differences, 117, 30-36. https://doi.org/ 10.1016/j.paid.2017.05.035

Ryff, C. D., \& Keyes, C. L. M. (1995). The structure of psychological well-being revisited. Journal of Personality and Social Psychology, 69(4), 719-727. https://doi.org/ 10.1037/0022-3514.69.4.719

Schotanus-Dijkstra, M., Pieterse, M. E., Drossaert, C. H. C., Westerhof, G. J., de Graaf, R., ten Have, M., Walburg, J. A., \& Bohlmeijer, E. T. (2016). What Factors are Associated with Flourishing? Results from a Large Representative National Sample. Journal of Happiness Studies, 17(4), 1351-1370. https://doi.org/10.1007/s10902-015-9647-3

Seligman, M. (2011). Flourish: A new understanding of happiness, well-being and how to achieve them. Nicholas Brealey Pub.

Sheldon, K. M. (2018). Understanding the good life. Eudaimonic living involves well-doing, not well-being. In Forgas, J. P., \& Baumeister R. F. (Eds.), The social psychology of living well (pp 116-136). New York: Routledge.

Silva, A. J., \& Caetano, A. (2013). Validation of the Flourishing Scale and Scale of Positive and Negative Experience in Portugal. Social Indicators Research, 110(2), 469-478. https://doi.org/10.1007/s11205-011-9938-y

Steger, M. F., Frazier, P., Oishi, S., \& Kaler, M. (2006). The meaning in life questionnaire: Assessing the presence of and search for meaning in life. Journal of Counseling Psychology, 53(1), 80-93. https://doi.org/10.1037/0022-0167.53.1.80

Sumi, K. (2014). Reliability and validity of Japanese versions of the Flourishing Scale and the Scale of Positive and Negative Experience. Social Indicators Research, 118(2), 601615. https://doi.org/10.1007/s11205-013-0432-6

Tong, K. K., \& Wang, Y. Y. (2017). Validation of the flourishing scale and scale of positive and negative experience in a Chinese community sample. PLOS ONE, 12(8), e0181616. https://doi.org/10.1371/journal.pone.0181616

Upmane, A. (2012). Factors predicting life satisfaction: quantitative and qualitative analysis. Doctoral Thesis. University of Latvia, Riga.

Villieux, A., Sovet, L., Jung, S.-C., \& Guilbert, L. (2016). Psychological flourishing: Validation of the French version of the Flourishing Scale and exploration of its relationships with personality traits. Personality and Individual Differences, 88, 1-5. https://doi.org/10.1016/j.paid.2015.08.027 